\title{
Hygroscopic larval provisions of bees absorb soil water vapor and release liquefied nutrients
}

\author{
James H. CANE ${ }^{1} \mathbb{D}$, and Byron G. Love ${ }^{1}$ \\ ${ }^{1}$ USDA-ARS Pollinating Insect Research Unit, USDA Bee Biology Lab, Utah State University, Logan, Utah 84322-5310,
} USA

Received 25 January 2021 - Revised 2 June 2021 - Accepted 21 July 2021

\begin{abstract}
Larvae of most bee species consume individual provision masses composed of pollen mixed with nectar. For simple metabolic reasons, mature larvae should weigh less than their consumed provision. However, past research reported a remarkable result: mature larvae of three ground-nesting halictid bees weighed $60 \%$ more than their original provision masses. This surprising paradox could result from the expected hygroscopic nature of nectar. Sugar solutions absorb water vapor at rates defined by their osmolarity and ambient humidity. Our experiments tested this hypothesis, showing that larval provisions of a ground-nesting bee, Nomia melanderi, are strongly hygroscopic. They consequently absorbed substantial water vapor from this bee's preferred nesting soil. Mature larvae weighed $65 \%$ more than their original provision because hygroscopy had greatly augmented available dietary water. Liquid accumulating around isolated provisions was a sweet nutritious broth that included amino acids leached from the pollen. Hygroscopy was most intense during the egg and early larval stages. However, provision liquefaction (and possible drowning) was partly offset by rapid hydration of cached pollen, whose weight could double after absorbing free water. Larval provisions of two cavity-nesting Osmia species also readily absorbed water vapor from a soil atmosphere. However, at humidities measured within tunnels of their natural deadwood nesting substrates, they gained little weight via hygroscopy. Consequently, their mature larvae weighed less, not more, than the provision that they ate. These new insights explain some nesting traits shared by many ground-nesting bees, such as why females do not waterproof the earthen cell caps of their nest cells, or why many colletids cache liquid provisions. Progressive hygroscopy and resulting sugar dilution may also mediate succession of microbial mutualists and pathogens in provision masses of ground-nesting bees.
\end{abstract}

\section{apiformes / water balance / nectar / nesting / nutrition / sugars}

\section{INTRODUCTION}

The diets of solitary bee larvae (and social halictids) generally consist of a mass of pollen mixed with nectar gathered and cached for each offspring by their mother. Nesting females assemble these larval diets as a mass provision; unlike honey bees, they do not progressively feed their progeny. The completed provision masses have a

Corresponding author: J. H. Cane,

Jim.Cane2@gmail.com

Handling Editor: James Nieh characteristic species-specific shape and texture, ranging from firm pasty spheroids to doughy masses to thick liquid suspensions on which larvae actually float (Malyshev 1935; Stephen et al. 1969; Radchenko and Pesenko 1994). Nesting substrates can also differ among bees. Most species nest underground where soil air humidities are always at or very near saturation (Hillel 1998). Other bees nest above-ground in deadwood tunnels, stems, or twigs whose internal humidities have not been measured.

Humidity of the nesting substrate is significant because the sugary mass provisions of bees 
are hygroscopic, as Malyshev (1935) first noted 80 years ago. Nonetheless, the water in larval bee provisions generally has been assumed to originate solely from nectar. Decades after Malyshev, studies of three different ground-nesting halictid bee species produced unexpected evidence consistent with a hypothesis that some of the bodily water in a mature bee larva must come not only from nectar but from the surrounding soil as well (Knerer 1969; Batra and Bohart 1970; May 1972). These authors discovered that mature, pre-defecating halictid bee larvae weighed much more than the average fresh provision mass eaten by their species. For example, mature larvae of Evylaeus malachurum Kirby weighed $60 \%$ more than their cached provision mass (Knerer 1969). That gain was speculatively attributed to progressive provisioning by the mother. Similarly, mature larvae of Nomia melanderi Ckll. and Augochlora pura (Say) weighed $59 \%$ and $62 \%$ more than their respective provision masses (Batra and Bohart 1970; May 1972). However, no maternal intervention was seen in their glass observation nests, thus negating Knerer's hypothesis. In addition, Batra and Bohart (1970) reported that the fractional water weight of larval $N$. melanderi increased with age, from $39 \%$ in young larvae to $72 \%$ in mature ones. These latter authors correctly surmised that the additional larval water gain must come from soil moisture. However, their methods could not distinguish between direct water uptake by larvae versus indirect gain by the hygroscopic provision mass. Paradoxically, females of these and nearly all other ground-nesting bees first apply a waterproof lining to the walls of their nest cells before provisioning (e.g., Hefetz et al. 1979; Cane 1981; Norden 1984). A waterproof lining seems at odds with any soil-borne water entering nest cells and provisions.

In this study, we experimentally sought the source, mechanism, and dynamics of water gain by individual pollen provisions and bee larvae. We focused on a representative groundnesting solitary bee, $N$. melanderi (the alkali bee). Provisioned nest cells were obtained from soil blocks dug from dense nesting aggregations (Cane 2008). These were sorted by life stage. Water contents were measured for growing larvae and their diminishing provision masses using a novel experimental design. Isolated fresh provisions were exposed to the atmosphere of their native nesting soil after adjusting it to the optimal water content preferred by nesting females. As with natural water-repellent nest cell linings, our set-up kept the provision mass from direct contact with the soil. The method was initially optimized using pollennectar pellets taken from honey bee foragers. To characterize the nutritional value of any accumulating "broth" for the developing larva, free water from around some hydrating provisions was removed and analyzed for both sugar and amino acid content arising from the nectar and leached pollen, respectively.

Unlike these ground-nesting halictids, mature larvae of a cavity nesting bee (Osmia cornuta) weighed less, not more, than their initial provision (Bosch and Vicens 2002). Two hypotheses could explain this contrast: larval provisions of Osmia may not be hygroscopic, or else deadwood tunnels are far less humid than soil air. We explored these hypotheses using captive populations of two cavitynesting bees, $O$. lignaria Say and $O$. sanrafaelae Parker (Megachilidae). The protocol for Nomia provision hydration was repeated, subjecting fresh Osmia provision masses to humidities of both soil and their deadwood nesting substrate. Airspace humidities in deadwood were also measured.

Most pollen is shed in a dehydrated state (Stanley and Linskens 1974). Its hydration has been studied on floral stigmas, but not in the context of larval bee provisions. To better understand hydrodynamics of larval pollen provisions as a function of water uptake by hydrating pollen itself, diverse freshly shed pollen species were exposed to saturated atmospheres to measure their water absorption. 


\section{MATERIALS AND METHODS}

\subsection{Weights and water contents of $\mathbf{N}$. melanderi larvae and their provisions}

Populous nesting aggregations of alkali bees are managed for alfalfa pollination and seed production near Touchet Washington USA (lat 46.0 $\left.\mathrm{N} \times 118.3^{\circ} \mathrm{W}\right)($ Cane 2008). From one newer aggregation, we excavated several $35-\mathrm{cm}$-deep soil blocks with many nests. We dissected these blocks to carefully open nest cells from which we obtained completed provision masses (Suppl. 1). Contents of opened cells were sorted by bee life stage. Cells with complete clean provisions (no dirt particles) with or without an egg (Suppl. 1) were reserved for hygroscopy studies. From other cells, developing larvae of diverse sizes (Suppl. 2) were taken for immediate weighing. On the day of excavation, each live larva and its provision remnant was first weighed separately, then dried at $100^{\circ} \mathrm{C}$ for $36 \mathrm{~h}$ and reweighed. To represent water content changes during larval development, we measured the wet and dry weights of larvae across a full range of sizes as well as their associated provision remnants. Like many other bees, these larvae do not begin defecating until late in development, simplifying these calculations.

\subsection{Hygroscopy of provision masses}

A $6 \mathrm{~L}$ sample of silty soil was dug from nest cell depth $(20 \mathrm{~cm})$ at the same managed nesting aggregation. The soil was loaded into 1-L lidded plastic tubs and lightly packed to crush soil pellets and eliminate air gaps. Soil moisture content was checked both by tensiometer, which measures soil-moisture tension or "matric suction" (Hillel 1998), and by weighing water lost after oven drying of small uniform soil cores. Moisture content of the prepared soil sample was then adjusted to match the 22 millibar matric suction of these soils at cell depth that was associated with maximum nesting densities in aggregations at Touchet Washington (Cane 2008).
To mimic conditions in a subterranean nest cell, complete provisions were individually exposed to the soil atmosphere without soil contact. In this way, provision weight gain could only result from water vapor absorption from the surrounding soil. For our experimental design, we first cut away the tapered tips of $1.5 \mathrm{ml}$ plastic micro-centrifuge tubes. This opening would serve as the air passage between the soil and provision mass. To hold a provision mass, a fitted mesh-floored cylindrical sleeve was inserted into each tube (e.g., Costar Spin-X centrifuge tube inserts from Corning Inc.) (Supplement 2). Eggs (if present) were removed, as were any stray dirt particles that fell on a provision's surface during excavation. To avoid handling provisions during daily weighings, each tube's sleeve was first weighed empty, then given a provision mass and reweighed. Each sleeve with its provision mass was then slipped into its respective microcentrifuge tube, its lid snapped shut, and the cut end of each tube snugly pressed about $2 \mathrm{~cm}$ into a premolded hole in the soil surface. Once all tubes were installed, the tub's cover was shut and the tub laid on its side so that tubes and sleeves were horizontal in the vertical soil face. This was necessary to retain accumulating hygroscopy liquid in the sleeve. Every $24 \mathrm{~h}$ for 8 days, sleeves with their contents were removed, individually weighed, and then promptly returned to their tube. Contents were visually inspected, noting any adhering free water or fungal hyphae. This setup was initially tested and optimized using batches of 15-20 fresh corbicular pollen pellets of honey bees (Apis mellifera L.), which were much more convenient to obtain than the larval provision masses of Nomia.

\subsection{Nutritional value of leachates from provision masses}

By the eighth day of hydration, every provision mass (or corbicular pellet) was visibly liquefying. In 2018, the hygroscopy experiment was repeated for the purpose of studying leachate chemistry. The free liquid that accumulated around a provision was removed and its volume 
measured by capillary micropipette before analyses for sugar and amino acid content. To quantify alfalfa nectar sugars in the free liquid, a $10-\mu \mathrm{l}$ aliquot was removed from each of 12 provisions. Because the alfalfa pollen leachate was clear (no visible pollenkitt pigments), we could use a standard colorimetric assay. We chose one that uses dinitrosalicylic acid (DNS) to specifically detect the reducing sugars glucose and fructose (Miller 1959) that typically dominate nectar of bee-pollinated flowers (Käpylä 1978). Sodium sulfite was added to remove dissolved oxygen, and after heating, color was stabilized using Rochelle salts. Absorbance was read by spectrophotometer at $575 \mathrm{~nm}$. A linear standard curve of incrementing concentrations of glucose was developed to estimate sugar amounts in the provision liquid.

After 5 and 8 days at saturated soil humidities, samples of leachate from eight Nomia provision masses were taken for amino acid and peptide analysis. These liquid samples were prepared for analysis by standard methods, starting with overnight acid hydrolysis. There followed derivatization using AQC and analysis by ultra-performance liquid chromatography (UPLC) with an AccuTAG Ultra C18 column (AccuTag amino analysis kit, Waters Inc., Milford Mass. USA). Both an internal standard and amino acid standards were used for quantification.

\subsection{Hygroscopy of provisions made by wood-nesting Osmia bees}

Water vapor uptake by fresh provision masses of the wood-nesting bees $O$. lignaria and $O$. sanrafaelae were measured for two contexts, that of $N$. melanderi nesting soil (Sect. 2.2) and also over a saturated $\mathrm{NaCl}$ solution whose humidity $(75 \%)$ approximates what we measured for sealed tunnels in suitable deadwood (Sect. 3.4). Humidities of tunnels drilled in deadwood were recorded for a series of sound tree snags and logs whose appearance and condition resembled those used for annual trap-nesting of Osmia species by the authors. Tree boles included both nine dead standing snags and two downed logs representing a range of circumferences $(75-176 \mathrm{~cm})$ and taxa (Populus, Pseudotsuga, Pinus). For each tree, a 1.2-cm-diameter hole was drilled radially to a typical nesting depth of $8 \mathrm{~cm}$. This tunnel diameter snugly accommodated a humidity sensor that is unusually accurate at high humidities (HMP50-L, Campbell Scientific, Logan, Utah, USA). The fresh hole was then corked shut for $30 \mathrm{~min}$ so air in the hole would equilibrate (as checked by sensor readings). The sensor was then slipped into the drill hole again and its lead wire sealed in place with a clay disk. Once the humidity sensor output had stabilized, the relative humidity of the cavity was recorded. To estimate wood water content, wood chips from drilling were collected, sealed up, weighed fresh, dried at $70{ }^{\circ} \mathrm{C}$ for $48 \mathrm{~h}$, and reweighed.

\subsection{Water uptake by hydrating fresh pollen}

Water vapor absorption was also quantified for freshly shed pure pollen taken from 11 plant species representing nine families (Table 1). Pollens of several of the genera (e.g., Alcea, Cucurbita) are known to be shed in a hydrated state, but most pollens are desiccated when shed (Stanley and Linskens 1974). Most pollen was harvested either by use of a vibrating tuning fork (e.g., catkins of Corylus and Salix) or by gently scraping large anthers of their sticky pollen (e.g., Cucurbita). For the paltry pollen production of alfalfa (Medicago sativa) flowers, female Megachile rotundata bees were intercepted at their nests after foraging in flowering, weed-free alfalfa seed fields. Foragers were first immobilized, and then, their loose dry pollen loads were swept from their scopae with a small brush. In all cases, collected pollen was amassed on a preweighed foil disk and weighed. The foil disk with pollen was then placed in a saturated atmosphere at $25{ }^{\circ} \mathrm{C}$ and reweighed twice again, after $24 \mathrm{~h}$ and $48 \mathrm{~h}$. To visually confirm pollen hydration, slide samples of Corylus taken before and after hydration were mounted in silicone oil to count the fraction of plump hydrated grains. 
Averages are presented with their standard deviations. Rates of hydration were regressed against days. Percent water weight gains of individual provisions were compared by species and substrate using a one-way ANOVA. An arcsin data transformation satisfied normality assumptions. Pairwise differences were compared for significance using the Holm-Sidak statistic (SigmaPlot 12.5, Systat, San Jose, Calif USA). The datasets generated during and/or analyzed during the current study are available from the corresponding author on reasonable request.

\section{RESULTS}

\subsection{Weights and water contents of $\mathbf{N}$. melanderi larvae and their provisions}

Weighed larvae represented the full range of body sizes and developmental instars. The combined weights of each of 37 freshly exhumed live larvae plus the remainders of their mass provisions were the greatest for larger, older larvae (Figure 1). Ultimately, the average final weights of seven full-grown predefecating larvae
$(246 \pm 28 \mathrm{mg})$ were $57 \%$ more than that of the average fresh weights of 19 newly made provisions $(148 \pm 13 \mathrm{mg})$. Six newly made provisions were $35 \%$ water $(55 \pm 5 \mathrm{mg})$. While larvae fed, the water fraction of the remaining provision gradually increased $\left(R^{2}=0.80, p<0.001, n=36\right)$, ultimately doubling over that of the original provision (Figure 1). Bodily water of seven mature predefecating Nomia larvae averaged 74\% $(182 \pm 26 \mathrm{mg})$, which was $>$ threefold more than the weight of water available from nectar alone in the original provision. Conversely, their average dry weight $(64 \pm 10 \mathrm{mg})$ was substantially less than the average dry weight of 19 intact provisions $(101 \pm 5 \mathrm{mg})$.

\subsection{Water weight gain of N. melanderi larvae and provisions}

All 28 provision masses of $N$. melanderi gained weight daily when exposed to the saturated water vapors emanating from nesting bed soils. The rate of water gain was not constant, but gradually decelerated following a hyperbolic curve (for 2019 trial, $R^{2}=0.93$,

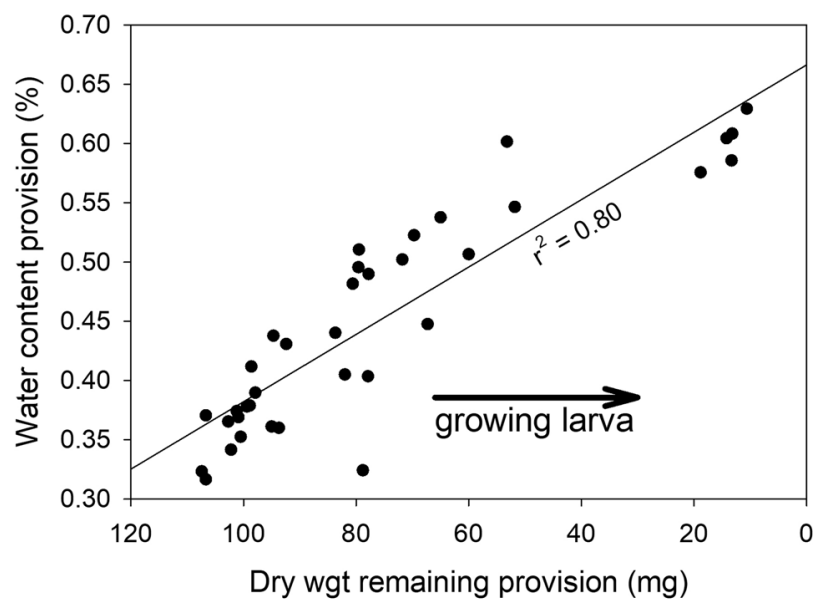

Figure 1. Increasing moisture of $N$. melanderi provision remainders over the course of the larval feeding period (larval growth indicated by diminishing dry weight of provision as it is consumed). Weights taken from 36 freshly exhumed nest cells. 


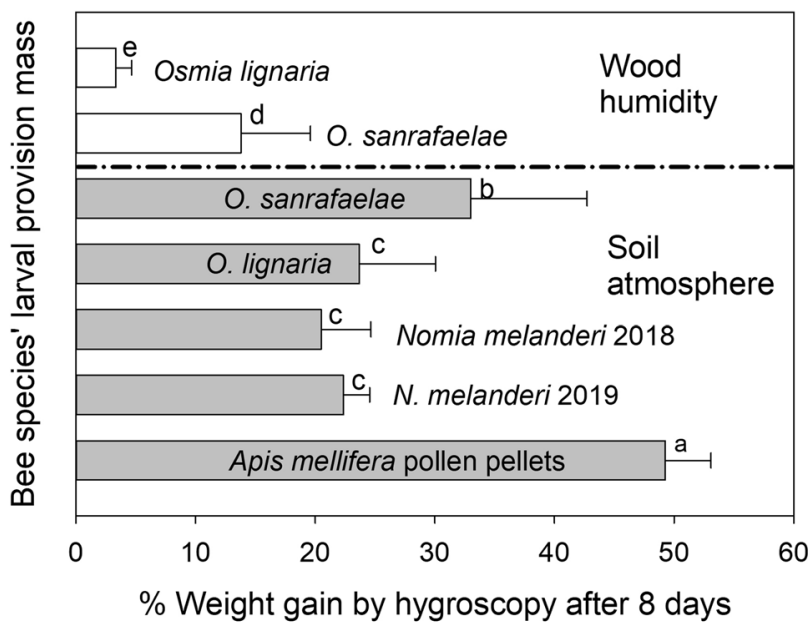

Figure 2. Percent weight gains of bee provisions (or honey bee pollen pellets) following 8 days exposed to either soil humidities or that of deadwood tunnels (75\% humidity). Bars bearing different lower case letters differ significantly by the Holm-Sidak a posteriori comparisons. Note that bar values are calculated from the original data and not back-transformed ones.

$p<0.0001, n=9$ ) (Figure 3). Experiments were ended after day 8 , as by then free liquid sometimes dripped from the sleeves, compromising weight gain measures. Weight gains for $N$. melanderi provisions were consistent between years (Figure 2).

\subsection{Sugar and amino acid content of water leaching from provision masses}

Reducing sugars (glucose and fructose) were present in the free water accumulating around every hydrating Nomia provision $(n=12)$. Sugars

Decelerating Hygroscopic Water

Weight Gain of N. melanderi provisions $f=(a * b) /(b+x)$

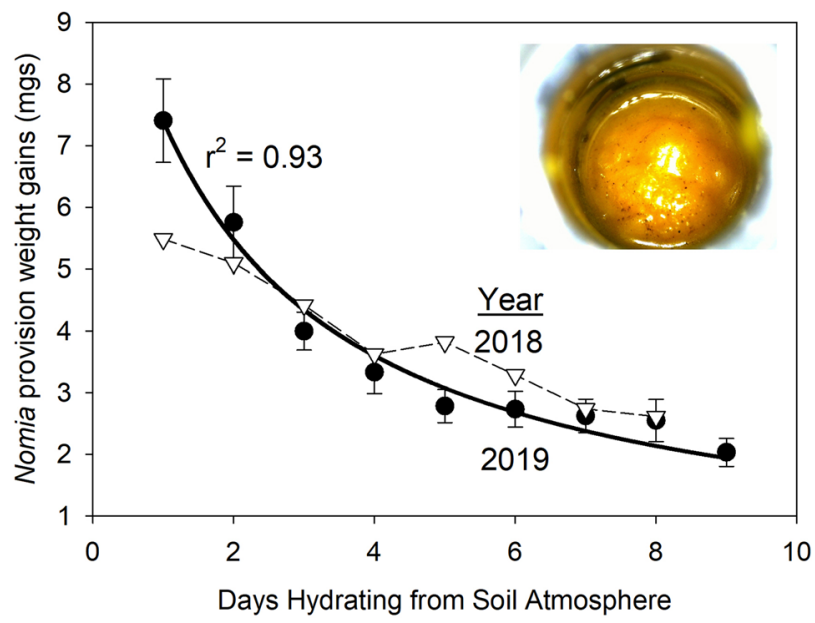

Figure 3. Decelerating daily weight gains of newly-made provision masses of $N$. melanderi (without larvae) during hygroscopic absorption of water vapor from soil atmosphere. New provisions collected and tested in 2018 and in 2019. 
in this leachate averaged $9.8 \pm 0.3 \mathrm{mg}$ per $10 \mu \mathrm{L}$ aliquot. Knowing that provisions averaged $55 \mathrm{mg}$ $(=55 \mathrm{uL})$ of water from nectar, we calculate that a provision originally contained $49 \pm 1.3 \mathrm{mg}$ sugar $(9.8 \mathrm{mg} \times 55 / 10 \mu \mathrm{L})$, or about $1 / 3$ of the overall weight of an average fresh provision (156 g).

Fourteen amino acids (or soluble peptides) were present and abundant in the free water that gradually accumulated around hygroscopic larval provisions (Figure 4). Between 5 and 8 days after initial hydration, ninefold more amino acids became available in the leachate (Figure 4). After 8 days of hygroscopic water uptake, the free liquid that we removed from around a given Nomia provision mass averaged $15 \pm 3 \mathrm{mg}$ of amino acids.

\subsection{Hygroscopy of provisions made by wood-nesting Osmia bees}

Holes drilled in dead tree trunks were consistently less humid than the saturated soil atmosphere. Wood of all sampled dead trees appeared sound; the average water content of wood chips from six trees was $17 \%$ (range $8-28 \%$ ). Relative humidities in sealed drill holes of ten snags and two downed logs averaged $73 \pm 8 \%$ (range $51-83 \%$ ). Larval provisions of Osmia species exposed to saturated soil humidities in the Nomia experiment gained weight hygroscopically like those of alkali bees (Figures 2, 5). However, Osmia provisions exposed to a close approximation of wood tunnel humidities $(75 \% \mathrm{RH}$, achieved over a saturated $\mathrm{NaCl}$ solution) absorbed little or no water (Figures 2, 5 ). In both contexts, provisions of $O$. sanrafaelae gained proportionally more weight from hygroscopy than did those of $O$. lignaria (Figure 2). Water from nectar constituted $21 \pm 3 \%(n=5)$ and $27 \pm 5 \%(n=8)$ of the weight of fresh provisions of $O$. lignaria and $O$. sanrafaelae, respectively, akin to those measured for $M$. rotundata $(20 \pm 2.5 \%, n=81)$ (Cane et al. 2011). Fresh leaf pulp partitions taken from $O$. sanrafaelae nests were considerably drier than their provision masses $(15 \pm 3 \%, n=5)$.

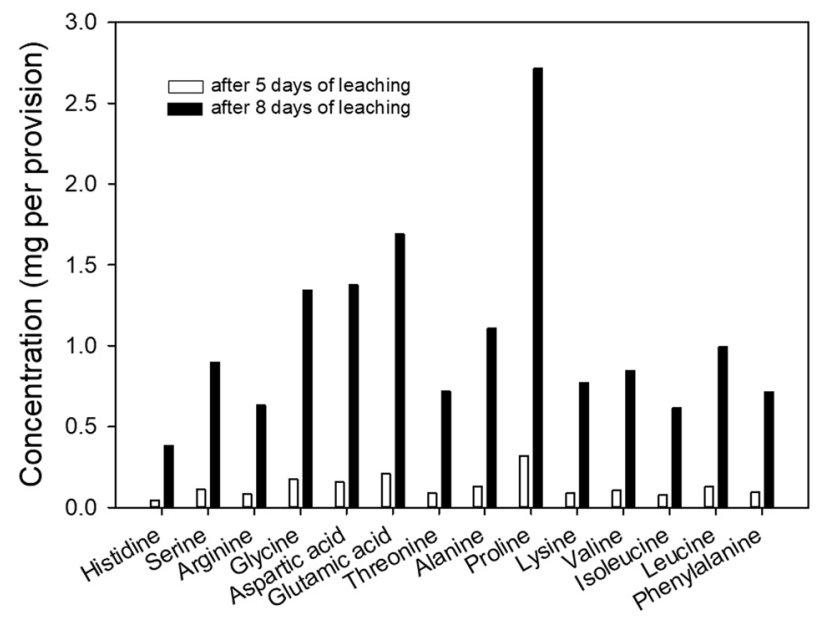

Amino acids leached from pollen provision

Figure 4. Amino acids leaching from provision masses of N. melanderi after 5 and 8 days of hygroscopic hydration from nesting soil water vapor. 


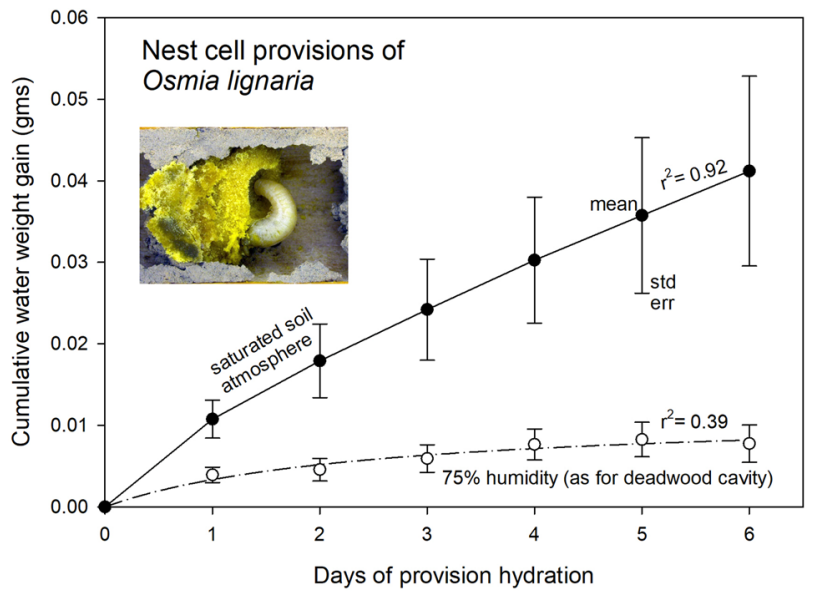

Figure 5. Daily water gain of newly-made provision masses of $O$. lignaria (without larvae) exposed to water vapors of either Nomia nesting soils or at $75 \%$ humidity, near the average humidity of tunnels drilled in dry deadwood.

\subsection{Water uptake by hydrating fresh pollen}

Loose pollen of most species quickly absorbed substantial water from a humid atmosphere (Table 1). Pollen of Corylus and Acer visibly swelled within seconds of contact with liquid water but did not germinate. After $48 \mathrm{~h}$ in a saturated atmosphere, $95 \%$ of Corylus pollen grains were similarly plumped by hydration. Loose pollen of representative species of Malvaceae, Convolvulaceae, and Cucurbitaceae lost half or more of their weight when oven dried, evidence of their being hydrated when shed. As expected, their pollen also hydrated the least among the species studied. In contrast, oven-dried freshly shed pollen of Helianthus had lost only $17 \%$ of its weight and Campsis just $8 \%$ (Table 1), illustrating their dehydrated state at anthesis.

\subsection{Water uptake by corbicular pellets of honey bees}

Corbicular pollen loads of honey bees were useful surrogates for testing and refining the hygroscopy assay. They were relatively dry $(8.0 \pm 0.16 \%$ nectar water, $n=5$ pooled samples $)$ compared to larval provision masses of Nomia and Osmia. However, they ultimately gained the most water weight during their 8 days of exposure to saturated soil humidities (Figure 2). Pellets added hygroscopic water at a near constant daily rate $\left(R^{2}=0.94, p<0.001,9\right.$ tubes) (Figure 6). Unlike bee provisions, fungal mycelia appeared on the surface of each group of pellets by the eighth day.

\section{DISCUSSION}

Whether or not a bee's mass provision gains water over time depends largely on the ambient humidities of nesting substrate cavities (Figure 2). Provisions of the ground-nesting bee $N$. melanderi were strongly hygroscopic when exposed to the atmosphere of their nesting soils (Figures 1, 3). In this soil-air context, provisions of two cavity-nesting Osmia species (Figures 2, 5), as well as honey bee corbicular pellets (Figures 2, 6), were also hygroscopic. Relative humidities of most soil atmospheres are at, or very near, saturation ( $>98 \%$ ) Conversely, Osmia provisions absorbed much less water at $75 \%$ humidity (Figures 2, 5), being the average humidity that we measured in tunnels of sound, dry tree snags and logs that these bees would use for nesting. Provisions of $O$. sanrafaelae initially contained more water from nectar than O. lignaria, and absorbed more moisture by 


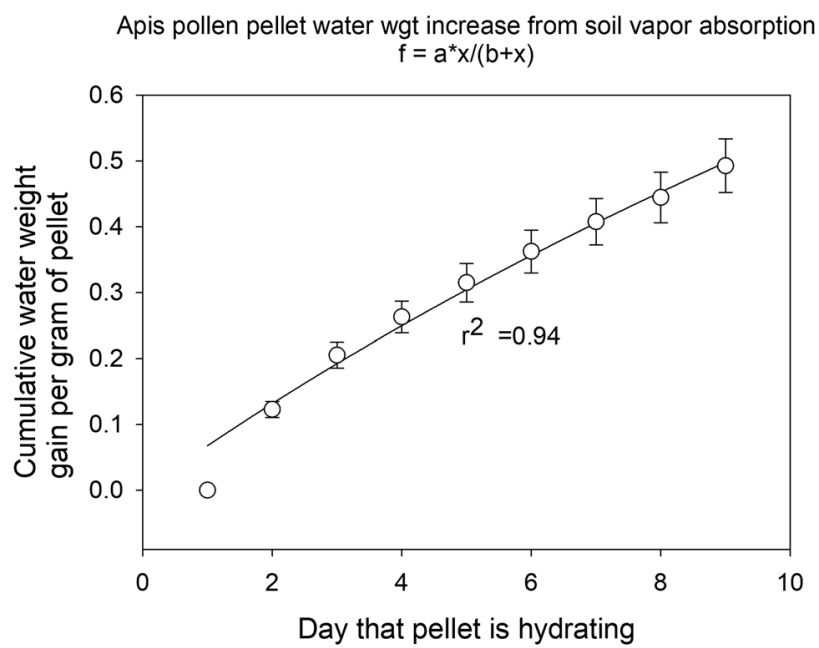

Figure 6. Daily water gain of fresh honey bee pollen pellets exposed to water vapors of $N$. melanderi nesting soils at the preferred soil moisture for their nesting.

hygroscopy in both humidity regimes (Figure 1), provisions (although they might support hydraillustrating how nectar constitution contributes tion of fresh pollen). For all mass provisions to provision hygroscopy as well. Fresh leaf pulp exposed to the soil atmosphere, hygroscopy was partitions against which provisions of $O$. sanrafaelae are piled were drier than the provisions, most intense at the outset of exposure, decelerating thereafter as a provision's nectar soluand so are not a source of hydration water for tion progressively diluted (Figures 4, 6). Since

Table I.. Water weight gain by hydrating pollen grains after $48 \mathrm{~h}$ at saturated humidity

\begin{tabular}{llll}
\hline Plant species & Family & Grain diam. (um) & $\begin{array}{l}\text { Water wt. } \\
\text { gain (or } \\
\text { loss) (\%) }\end{array}$ \\
\hline Balsamorhiza sagitatta & & & 60 \\
Helianthus annuus & Asteraceae & 25 & 95 \\
Corylus americana & Asteraceae & 39 & 37 \\
Campsis radicans $_{\text {Ipomoea purpurea }}$ & Betulaceae & 26 & 75 \\
Cucurbita pepo $_{\text {Dalea searlsiae }}$ & Bignoniaceae & 12 & 75 \\
Medicago sativa & Convolvulaceae & 70 & 33 \\
Alcea rosea & Cucurbitaceae & 160 & 133 \\
Callirhoe involucrata & Fabaceae & 23 & 103 \\
Malus sylvestris & Fabaceae & 33 & -7 \\
Salix caprea & Malvaceae & 110 & 2 \\
\hline & Malvaceae & 80 & 55 \\
\hline
\end{tabular}

\footnotetext{
${ }^{1}$ Ipomoea pollen became immersed in a pool of liquid after $24 \mathrm{~h}$, which was ropy in texture. Microscopic examination revealed abundant fungal hyphae and bacteria. This response was not observed with other concurrently run species. The same response ensued with new fresh pollen; washing all glassware surfaces with detergent and ethanol did not prevent the response
} 
larvae are the smallest when hygroscopy is most intense, it follows that young larvae must be ingesting a largely liquid diet, as Rozen (1967) surmised from his intranest observations of larval panurgine bees.

The watery leachate that accumulated around larval provision masses is nutritious, containing both carbohydrates (monosaccharides) and amino acids and/or peptides (Figure 4). The sugars in bee provisions come from nectar (Cane et al. 2011), so their presence is expected in the aqueous leachate. There may be metabolic competition for these nectar sugars between the feeding larva and the yeasts or bacteria known to be able to proliferate in a freshly made provision mass of N. melanderi (Batra et al. 1973). Amino acids also leached from hydrating pollen in the bee provisions. Studies of petunia pollen show that free amino acids are quickly released by germinating pollen, particularly proline, which is both abundant and exists primarily as a free amino acid in the germinated pollen (Linskens and Schrauwen 1969). Hence, at least some release of amino acids from pollen in provisions occurs without the intercession of microbial metabolism. The quantities leached increased dramatically between the fifth and eighth days of provision hydration (Figure 4). This increase may result from bacteria or yeasts gradually entering pollen grains to digest their contents, but such entry has not been reported. The 14 amino acids detected in the provision leachates included eight of the ten essential amino acids known for honey bees (de Groot 1953). Just five amino acids together comprised half of the amount eluting from provisions (Figure 4). These same five amino acids prevailed in a large survey of bee-collected pollens (Weiner et al. 2010). For honey bees, at least, these five amino acids are not dietarily essential (de Groot 1953).

Most pollen species absorbed half or more of their fresh weight upon hydration (Table 1). Hydration water doubled the weight of fresh alfalfa pollen ( $M$. sativa), which is the pollen cached by female $N$. melanderi in this study. The shed pollen of tested species of Malvaceae, Convolvulaceae, and Cucurbitaceae hydrated the least and lost half or more of their weight when oven dried (Table 1). Their large, spherical grains lack the sutures than enable folding upon desiccation. Consequently, they are shed partially hydrated rather than desiccated. In contrast, Helianthus pollen only lost $17 \%$ of its weight and Campsis pollen just $8 \%$ when oven dried, indicative of their desiccated state when shed (Table 1). Thus, most pollen contributes negligible water to a provision mass (and feeding larva). Instead, most pollen species are expected to quickly absorb substantial water as the nesting female adds nectar to the growing provision. Serving as a sponge, pollen hydration should delay liquefaction of larval provisions by ensuing hygroscopy, thereby helping protect the young larva from drowning. Consistent with this insight, provisions made by the ground-nesting Cucurbita specialist Peponapis pruinosa are initially "very fluid" (Mathewson 1968), in part because the pollen of its floral host is already hydrated when shed, and so does not withdraw nectar when mixed in a provision mass.

Provision masses of $N$. melanderi were less uniform than honey bee pollen pellets in their rates of hygroscopic water absorption (Figure 3 vs. Figure 6). One likely source of this variability among individual provision masses is the ages of intact provisions at the time of excavation. We used the presence of an egg to indicate that a provision was complete and relatively new, but because the egg stage of $N$. melanderi can take 4-5 days to hatch (Hackwell and Stephen 1966; Batra 1970), we undoubtedly experimented with provision masses of somewhat different ages. If a provision was just 2 days old when excavated, then it would already have absorbed $>20 \mathrm{mg}$ of water in the field before we removed it for experimentation (Figure 3 ). In this scenario, the soil atmosphere would contribute as much water (about $53 \mathrm{mg}$ ) as did nectar to the developing larva. The difference between our two year's results (Figure 3 ) could easily have arisen from such differences in average age of excavated provision masses.

Rates of provision mass hygroscopy will be influenced by several attributes of the floral nectar source. Although typical nectar sugars are calorically equivalent, they do differ in another 
trait relevant to provisions of ground-nesting bees; fructose is far more hygroscopic than sucrose or glucose. Young larvae fed provisions moistened with fructose-rich nectars will need to imbibe leachate more quickly to avoid potential drowning. Sugar concentrations of floral nectars also vary widely, both by species and in response to weather conditions (Corbet et al. 1979), which obviously affects caloric content as well as bees' ability to imbibe the nectar (Roubik et al. 1995). Foraging females may further concentrate nectar, as they sometimes pause during foraging trips to manipulate a regurgitated nectar droplet on their tongue (e.g., Batra 1966), a behavior described for worker honey bees in the colony (Park 1932). In other cases, sugar concentration of nectar in the crop may match that of flowers at the same hour (Neff and Simpson 1990). Regardless, the hygroscopic significance of nectar concentration in larval provisions is now apparent too. Newly secreted nectar is always dilute. As a day progresses, evaporation concentrates the sugars in nectar at a rate dictated by relative humidity (Bertsche 1983), temperature, wind speed, and floral morphology (Corbet et al. 1995); at Texas sunflowers, nectar concentration doubled by noon (Neff and Simpson 1990). This diurnal progression can be interrupted when a flower replenishes nectar following its withdrawal by a floral visitor (e.g., Castellanos et al. 2002). Provisions made early in the day, or on humid days, or after a rain shower, should be less hygroscopic because the source nectar will be more dilute, whereas on warm dry afternoons, remaining nectar will be more concentrated (e.g., Neff and Simpson 1990), yielding much more sugary provision masses. A provision made by the same bee a few hours later using this far sweeter nectar will absorb substantially more water vapor from the soil atmosphere, ultimately resulting in mature larvae with more bodily water (unless mother bees compensate by altering the pollen:nectar ratios of their provisions). This will certainly benefit larvae nutritionally by providing more dietary calories in the initial provision mass, provided young larvae can imbibe apace of the forming leachate to avoid drowning. Some of these questions about nectar concentration and hygroscopy could be studied using honey bee corbicular pellets as a convenient and reasonable surrogate for bee provisions, although they should be partly hydrated to a water content equivalent to that of the larval bee provision of interest (Figure 2).

Two groups of solitary bees with distinctive nesting habits contrast with this model of gradual provision hydration for ground-nesting species, but their differences serve to support the model. The first group is those solitary bees (mostly Megachilidae) that nest above-ground in cavities, with no soil contact. The few megachilid species with comparable larval and provision weight measures conform to the typical expectation that herbivores weigh less than the sum of plant material that they consumed. Thus, the average mature larva of the bee Osmia cornuta, including its cocoon and frass, weighed $33 \%$ less than their average pollen provision. An average fresh provision of the alfalfa leaf-cutting bee, $M$. rotundata, weighs $94 \mathrm{mgs}$ but resulting mature larvae just starting to spin their cocoons weighed $50 \%$ less (48 $\pm 5 \mathrm{mg}, n=9)$ (Theresa Pitts-Singer, unpubl. data). Nectar sugar content of $M$. rotundata provisions (Cane et al. 2011) is comparable to what we estimated for $N$. melanderi. In one study, adding water to $O$. lignaria larval provisions did not increase their progeny's final weights (Burkle and Irwin 2009). Conversely, Osmia provisions held at approximate deadwood cavity humidities $(75 \%)$ did not lose moisture by evaporation either. For such cavity-nesting bees, mature larvae weigh less, not more, than their cached diet, for the usual metabolic reasons of digestive inefficiency, indigestible components and energetic loss, possibly compounded by water loss (although not from provision evaporation).

The second exception is various groundnesting bees of the family Colletidae. Their females spread secreted macrocyclic lactones (in some cases mixed with silk) onto the smoothed soil walls of their nest cells, where they polymerize to form a waterproof membrane. Species of Colletes and Hylaeus go further, closing each cell with the same membrane, thereby sealing the entire cell. These waterproofed cell walls of both Colletinae 
and Diphaglossinae (Rozen 1984; Houston 2020a) form a vessel to hold the liquid provisions cached by nesting females. Their larvae are adapted to feed while afloat. In contrast, pasty solid provision masses are typical of many halictids (e.g., Nomia), andrenids, some other colletids (e.g., Leioproctus (Houston 2020b)), and some Apidae. Unlike our study with $N$. melanderi, wherein hygroscopic provisions gradually absorbed water from the soil atmosphere to supplement dietary water in their pasty provision, nesting colletid females apparently provision enough nectar to satisfy all of their offspring's needs for dietary water. Female Ptiloglossa arizonensis (Colletidae) collected the copious nectar of Agave parryi at dawn (Rozen 1984) to create liquid larval provisions. Because nectar at that hour is very dilute (13-17\% dissolved solids) (Slauson 2000), it is not hygroscopic, and consequently, the unlined earthen cell plugs of $P$. arizonensis are not expected to be conduits for soil water vapor, unlike the unlined nest plugs of most other ground-nesting bees. The sweet liquid provisions of many colletids should be immediately susceptible to microbial proliferation as well. In fact, Roberts (1971) noted that liquid provisions of the tropical colletid P. guinnae bubbled, the gasses presumably generated by yeasts that he isolated from the liquid provisions. He speculated that the unlined cell cap allowed these fermentation gasses to escape the cell. These colletid bees have taken a different evolutionary path from other ground-nesting solitary bees for securing sufficient water for their offspring's diet.

Some other solitary bees fortify their larval provisions with hydrophobic lipids. Some species of Anthophora, Habropoda, and groundnesting Megachile secrete liquid triglycerides from their abdominal Dufour's gland. They mix these lipids into the larval provision mass. For Anthophora, at least, intranest observations confirmed that these lipids supplement nectar that is also regurgitated into the growing provision mass (Norden et al. 1980). The other source of lipids in some larval provisions is floral oils. A few bee genera of two different families (Melittidae,
Apidae) collect these floral oils from a diverse array of plant genera and families. By blending either secreted triglycerides or floral oils into the larval pollen provision, these bees presumably diminish hygroscopic uptake of soil water vapor into the provision, which begs the question of how their larvae gain sufficient dietary water. Some of these species further impede water vapor flow from the soil atmosphere by how they complete their nest cells.

A gas-permeable nest cell plug seems necessary for respiratory gas exchange between the soil atmosphere and the metabolically active larva in the nest cell. Most ground-nesting bees cap their nest cells with unlined, water-permeable soil plugs (e.g., Rozen 1967), although females could readily smooth and waterproof the outside of the cap to prevent inundation and flooding after intense rainfall. Among ground-nesting bees, only females of some Anthophora and Habropoda species (Apidae) are known to apply a waterproof coating to the interior of their soil nest caps (Stephen et al. 1969; Norden 1984). As with the aforementioned colletids, this waterproofed soil cap should impede or bar the passage of soil water vapor into the nest cell, preventing hygroscopic water gain by the provision mass. As a consequence, the mature larva must obtain all of its dietary water from the provision mass (and perhaps metabolic water). As with woodand twig-nesting bees, these ground-nesters living in fully sealed nest cells must possess as yet unknown adaptations for accumulating and/or retaining adequate body water as larvae.

The comparative development of microbial communities in larval bee provisions should reflect the strongly contrasting rates of provision hygroscopy that we have found between soil- and cavity-nesting bees. Larval provisions of the two Osmia species did not absorb water vapor at the ambient humidities that we measured for their deadwood nest tunnels. Consequently, their provisions should present stable water potentials to colonizing bacteria, yeasts and filamentous fungi. One species, Lactobacillus kunkeei, is abundant in both honey and flowers, is osmophilic, and prospers on fructose media (Endo and Salminen 2013). A sister species, L. micheneri, 
was found in larval provisions of seven cavitynesting megachilds as well as halictids nesting in soil or rotten wood (McFrederick et al. 2017). It has genes relevant to its existence in nectar and larval provisions, including ones for osmotolerance (Vuong and McFrederick 2019). Provisions of most ground-nesting bees should initially favor proliferation of these more osmophilic species, some of which Batra et al. (1973) isolated from dead eggs, sickened larvae and spoiling provisions of $N$. melanderi. One yeast that they isolated from Nomia provisions, Metschnikowia pulcherrima, they also found abundantly in the fermenting provisions of Ptiloglossa bees being consumed by seemingly healthy larvae. They reported isolating filamentous soil fungi, especially Aspergillus flavus, from diseased larvae and spoiled provisions of multiple groundnesting bee species. The Batra's inoculations of in situ N. melanderi provisions showed that $A$. flavus only developed secondarily, apparently unable to colonize newly-made provisions with their greater water potentials.

Why do female alkali bees require silty damp nesting soils with a salty surface (Stephen 1960)? Where managed nesting beds are inadequately sub-irrigated, nesting females either dig deeper main tunnels until damper soils are attained (Johansen et al. 1978), or abandon the nest site altogether (Cane 2008). In arid southeastern Washington state, alfalfa seed growers that manage alkali bees subirrigate nesting sites to attain uniformly damp nesting soils for their bees. Moist soil was thought to be necessary for suitable water relations of provisions and larvae. However, this explanation now seems unlikely, given the near-saturated state of soil air spaces in general (Hillel 1998) and our demonstration of relatively consistent hygroscopic hydration of provision masses despite differing water contents of the provided nesting soils.

We suggest a different explanation for bees' soil moisture preferences, being the physical malleability of the soil at cell depth. This should be critical to final cell wall preparation. Females of most bees that dig underground nests bear a small flat raised triangular surface, the pygidial plate, that is atop the dorsal tip of their metasoma (Michener 2007). By curling her abdominal tip ventrally, the digging female's pygidial plate is brought to face the soil surface. In this position, females then pack the soil of their cell walls by rapidly tamping the tip against the soil surface. Only then do females apply a typically thin waterproof coating secreted by their Dufour's gland (Cane 1981). Tamping followed by lining application has been evidenced by the triangular imprints of the pygidium in earthen cell walls (e.g., Rozen 1984) and was visually confirmed using glass-walled observation nests (Batra 1968; Roberts 1969; Norden 1984). Pygidial tamping forms a smooth cell wall surface, given a suitably damp soil. A drier soil might resist tamping, leaving rougher nest cell walls. This may be the reason that females of some desert species add regurgitated liquid to dry cell walls before tamping (Cane and Rozen 2019). Presumably, rougher walls would require more secretion to coat surface imperfections well enough to bar invasion by deleterious soil-borne bacteria and fungi. Thus, the moister soil strata seemingly sought by tunneling ground-nesting females for nest cell placement (JHC, pers. obs.) may be for purposes of fine soil sculpting rather than water relations of provisions or larvae.

As a closing climatic caveat, we note that our research was set in the arid US Intermountain West. The hygroscopic nature of mass provisions and larval water relations of Nomia should be representative of many ground-nesting species, because all soil atmospheres should be at or near saturation. For deadwood substrates, we measured internal humidities in arid Utah. Conceivably, larval provisions of wood- and stemnesting species living in more humid climates (i.e., places with nightly dews) might absorb more water vapor under field conditions.

\section{SUPPLEMENTARY INFORMATION}

The online version contains supplementary material available at https://doi.org/10.1007/s13592-021-00883-5. 


\section{ACKNOWLEDGEMENTS}

We are grateful to the generous help given us by multiple people. Dr. Mark Berhow, Research Chemist at NCAUR (USDA, ARS, in Peoria, Ill. USA), ran our leachate samples on their Waters Amino Acid Analyzer and provided his calculations from the raw UPLC data. Sarah Clark at Whitman College kindly arranged for our daily access to both a lab oven and a sensitive balance. Dr. Galen Campbell of Decagon Instruments (Pullman, Wash.) generously shared his measures and interpretations of water potentials using his custom instrumentation. John Dodd provided us with quality lab bench space at the Forage Genetics facility in Touchet. Helpful reviews were provided by Terry Houston and Quinn McFrederick.

\section{AUTHOR CONTRIBUTION}

JHC conceived, co-designed and implemented experiments, analyzed data, and wrote the manuscript. BGL helped optimize design and substantially contributed to data collection and summarization/calculation, contributed key design refinements, and with JHC, collected and compiled data.

\section{DATA AVAILABILITY}

The datasets for the current study are available from the corresponding author on reasonable request.

\section{DECLARATIONS}

\section{Ethics approval Not applicable.}

Competing interests The authors declare no competing interests.

Open Access This article is licensed under a Creative Commons Attribution 4.0 International License, which permits use, sharing, adaptation, distribution and reproduction in any medium or format, as long as you give appropriate credit to the original author(s) and the source, provide a link to the Creative Commons licence, and indicate if changes were made. The images or other third party material in this article are included in the article's Creative Commons licence, unless indicated otherwise in a credit line to the material. If material is not included in the article's Creative Commons licence and your intended use is not permitted by statutory regulation or exceeds the permitted use, you will need to obtain permission directly from the copyright holder. To view a copy of this licence, visit http://creativecommons.org/licenses/by/4.0/.

\section{REFERENCES}

Batra, L.R., Batra, S.W.T., Bohart, G.E. (1973) The mycoflora of domesticated and wild bees (Apoidea). Mycopathologia et Mycologia applicata. 49, 13-44

Batra, S.W.T. (1966) The life cycle and behavior of the primitively social bee, Lasioglossum zephyrum (Halictidae). Univ. Kansas Sci. Bull. 46, 359-423

Batra, S.W.T. (1968) Behavior of some social and solitary halictine bees within their nests: a comparative study. J. Kansas Entomol. Soc. 41, 120-133

Batra, S.W.T. (1970) Behavior of the alkali bee, Nomia melanderi, within the nest (Hymenoptera: Halictidae). Ann. Entomol. Soc. Amer. 63, 400-406

Batra, S.W.T., Bohart G.E. (1970) Brood care in halictid bees. Science. 168, 875

Bertsche, A. (1983) Nectar production of Epilobium angustifolium at different air humidities; nectar sugar in individual flowers and the optimal foraging theory. Oecol. 59, 40-48

Bosch, J., Vicens, N. (2002) Body size as an estimator of production costs in a solitary bee. Ecol. Entomol. 27, 129-137

Burkle, L., Irwin, R. (2009) Nectar sugar limits larval growth of solitary bees (Hymenoptera: Megachilidae). Environ. Entomol. 38, 1293-1300

Cane, J.H. (1981) Dufour's gland secretion in the cell linings of bees (Hymenoptera: Apoidea). J. Chem. Ecol. 7, 403-410

Cane, J.H. (2008) A native ground-nesting bee (Nomia melanderi) sustainably managed to pollinate alfalfa across an intensively agricultural landscape. Apidologie. 39, 315-323

Cane, J.H., Gardner, D.R., Harrison, P.A. (2011) Nectar and pollen sugars constituting larval provisions of the alfalfa leaf-cutting bee (Megachile rotundata) (Hymenoptera: Apiformes: Megachilidae). Apidologie. 42, 401-408

Cane, J.H., Rozen, J.G. Jr. (2019) Appendix: The desert bee Caupolicana yarrowi (Colletidae) uses nectar for nest construction. Amer. Mus. Novitates. 3931, 18-20

Castellanos, M.C., Wilson, P., Thomson, J.D. (2002) Dynamic nectar replenishment in flowers of Penstemon (Scrophulariaceae). Amer. J. Bot. 89, 111-118

Corbet, S.A., Saville, N.M., Fussel, 1 M., Prysjones, O.E., Unwin, D.M. (1995) The competition box: a graphical aid to forecasting pollinator performance. J. Appl. Ecol. 32, 707-719

Corbet, S.A., Willmer, P.G., Beament, J.W.L., Unwin, D.M., Prŷs-Jones, O.E. (1979) Post-secretory determinants of sugar concentration in nectar. Plant Cell Envir. 2, 293-308 
Endo, A., Salminen, S. (2013) Honeybees and beehives are rich sources for fructophilic lactic acid bacteria. Syst. Appl. Microbiol. 36, 444-448

de Groot, A.P. (1953) Protein and amino acid requirements of the honeybee (Apis mellifica L.). Physiol. Comp. Oecol. 3, 197-285

Hackwell, G.A., Stephen, W.P. (1966) Eclosion and duration of larval development in the alkali bee, Nomia melanderi (Hymenoptera-Apoidea). PanPacific Entomol. 42, 196-200

Hefetz, A., Fales, H.M., Batra, S.W.T. (1979) Natural polyesters: Dufour's gland macrocyclic lactones for brood cell laminesters in Colletes bees. Science. 204, 415-417

Hillel, D. (1998) Environmental soil physics. New York: Elsevier

Houston, T.F. (2020a) Nesting biology of the Australian solitary bee Paracolletes crassipes Smith (Hymenoptera: Colletidae) accords with that of the Diphaglossinae. Rec. West. Australia Mus. 35, 53-62

Houston, T.F. (2020b) On the nesting biology of a solitary bee in the subgenus Leioproctus (Goniocolletes) (Hymenoptera: Colletidae) in south-western Australia. Austral. Entomol. 47, 83-92

Johansen, C.A., Mayer, D.F., Eves, J.D. (1978) Biology and management of the alkali bee, Nomia melanderi Cockerell (Hymenoptera: Halictidae). Melanderia. 28, 25-46

Käpylä, M. (1978) Amount and type of nectar sugar in some wild flowers in Finland. Ann. Botan. Fennici. 15, 85-88

Knerer, G. (1969) Brood care in halictine bees. Science. 164, 429-430

Linskens, H.F., Schrauwen, J. (1969) The release of free amino acids from germinating pollen. Acta Botan. Neerlandica. 18, 605-614

Malyshev, S.I. (1935) The nesting habits of solitary bees: a comparative study. EOS Revista Espanola Entomol. 11, 201-309

Mathewson, J.A. (1968) Nest construction and life history of the eastern cucurbit bee Peponapis pruinosa (Hymenoptera: Apoidea). J. Kansas Entomol. Soc. 41,2, 255-261

May, D.G.K. (1972) Water uptake during larval development of a sweat bee, Augochlora pura (Hymenoptera: Apoidea). J. Kansas Entomol. Soc. 45, 439-449

McFrederick, Q.S., Thomas, J.M., Neff, J.L., Vuong, H.Q., Russell, K.A., Hale, A.R., Mueller, U.G. (2017) Flowers and wild megachilid bees share microbes. Microb. Ecol. 73, 188-200

Michener, C.D. (2007) The bees of the world. Baltimore: Johns Hopkins Univ. Press

Miller, G. (1959) Use of dinitrosalicylic acid reagent for determination of reducing sugar. Anal. Chem. 31, 426-428

Neff, J.L., Simpson, B.B. (1990) The roles of phenology and reward structure in the pollination biology of wild sunflower (Helianthus annuus L., Asteraceae). Israel J. Bot. 39, 197-216
Norden, B.B. (1984) Nesting biology of Anthophora abrupta (Hymenoptera: Anthophoridae). J. Kansas Entomol. Soc. 57, (2):243-262

Norden B., Batra S.W.T., Fales H.F., Hefetz A., Shaw G.J. (1980) Anthophora bees: unusual glycerides from maternal Dufour's glands serve as larval food and cell lining. Science. 207, 1095-1097

Park, O.W. (1932) Studies on the changes in nectar concentration produced by the honeybee, Apis mellifera. Part I. Changes which occur between the flower and the hive. Iowa Agric. Home Econ. Exper. Sta. Res. Bull. 151, 211-243

Radchenko, V.G., Pesenko, Y.A. (1994) Biology of bees (Hymenoptera: Apoidea). St. Petersburg: Russian Academy of Sciences

Roberts, R.B. (1969) Biology of the bee genus Agapostemon (Hymenoptera: Halictidae). Univ. Kansas Sci. Bull. 48, 689-719

Roberts, R.B. (1971) Biology of the crepuscular bee Ptiloglossa guinnae n.sp. with notes on associated bees, mites, and yeasts. J. Kansas Entomol. Soc. 44, 283-294

Roubik, D.W., Yanega, D., Aluja, M., Buchmann, S.L., Inouye D.W. (1995) On optimal nectar foraging by some tropical bees (Hymenoptera: Apidae). Apidologie. 26, 197-211

Rozen, J.G.J. (1967) Review of the biology of panurgine bees, with observations of North American forms (Hymenoptera, Andrenidae). Amer. Mus. Novitates. 2297, 44

Rozen, J.G. Jr. (1984) Nesting biology of diphaglossine bees (Hymenoptera, Colletidae). Amer. Mus. Novitates. 2786, 1-33

Slauson, L.A. (2000) Pollination biology of two chiropterophilous agaves in Arizona. Amer. J. Bot. 87, 825-836

Stanley, R.G., Linskens, H.F. (1974) Pollen: Biology, biochemistry, management. Heidelberg, Germany: Springer-Verlag

Stephen, W.P. (1960) Artificial beds for the propagation of the alkali bee, Nomia melanderi. J. Econ. Entomol. 53, 1025-1030

Stephen, W.P., Bohart, G.E., Torchio, P.F. (1969) The Biology and External Morphology of Bees. Corvallis: Agricul. Exper. Sta. Oregon St. Univ

Vuong, H.Q., McFrederick, Q.S. (2019) Comparative genomics of wild bee and flower isolated Lactobacillus reveals potential adaptation to the bee host. Genome Biol Evol. 11, 2151-2161

Weiner, C.N., Hilpert, A., Werner, M., Linsenmair, K.E., Blüthgen, N. (2010) Pollen amino acids and flower specialisation in solitary bees. Apidologie. 41, 476-487

Publisher's Note Springer Nature remains neutral with regard to jurisdictional claims in published maps and institutional affiliations. 